\title{
Analysis on the potential of ecological water replenishment for Baiyangdian Lake by reservoirs in the mountainous area of Daqing River
}

\author{
Yanyu Dai ${ }^{1,2,}{ }^{*}$, Siqi Wang ${ }^{1}$, Hongpeng $\mathrm{Zhu}^{3}$, Yiran $\mathrm{Xu}^{1}$ \\ ${ }^{1}$ Water Resources Institute, China Institute of Water Resources and Hydropower Research, Beijing 100038, China \\ ${ }^{2}$ College of Hydrology and Water Resources, Hohai University, Nanjing 210000, China. \\ ${ }^{3}$ Baoding Water Administration Detachment of Hebei Province, Baoding 071000, China
}

\begin{abstract}
Reservoirs in the Daqing River mountainous area have always been an important source of replenishment for Baiyangdian Lake. With the development of water source economy and society, the reservoir's ecological water replenishment potential for Baiyangdian Lake will undergo great changes. This article first analyzes the current situation of ecological water replenishment in Baiyangdian Lake. On this basis, the ecological water supply potential of the upstream reservoir to Baiyangdian Lake in the future was calculated. The results of the study show that from 2001 to 2018, the amount of water entering the upper reaches of the reservoir showed an overall upward trend, and the upward trend of runoff from the Xidayang Reservoir was the most obvious. Under different incoming water conditions, the ecological water supply potential of the upstream reservoir to Baiyangdian varies greatly. It can reach 320 million $\mathrm{m}^{3}$ in a wet year and only 50 million $\mathrm{m}^{3}$ in a dry year. In the continuous dry years, the average multi-year water supply potential of the reservoirs to the river and Baiyangdian Lake is about 146 million $\mathrm{m}^{3}$. The results of this paper can be used as a reference for Baiyangdian Lake's ecological water replenishment scheduling
\end{abstract}

\section{Introduction}

Baiyangdian (BYD) Lake is the largest shallow freshwater wetland in the North China Plain. It is located in the middle reaches of the Daqing River and has the reputation of "Pearl of North China" and "Kidney of North China". The water level was too low (below 5 meters) for five consecutive years from 1983 to 1988 , and this situation has occurred many times thereafter. In order to restore the ecology of BYD Lake, the Wangkuai Reservoir (WK), Xidayang Reservoir (XDY) and Angezhuang Reservoir (AGZ) in the Daqinghe mountainous area have repeatedly supplemented BYD Lake ecological water, and supplemented BYD Lake ecological water with water from the Yellow River and the middle route of the Southto-North Water Diversion. The planning outline for Xiongan New Area proposes to establish a multi-source water replenishment mechanism, coordinate the water diversion from the Yellow River, upstream reservoirs and local unconven-tional water resources, and rationally regulate the ecological and hydrological processes of BYD Lake. In recent years, scholars have commented on the ecological water demand of BYD Lake ${ }^{[1]}$, the evolution characteristics of wetland water resources ${ }^{[2,3]}$, and the characteristics of the inflow of the upstream reservoirs of BYD Lake ${ }^{[4]}$, and the influencing factors of runoff ${ }^{[5]}$, the characteristics of abundance and dryness ${ }^{[6]}$, and the joint operation of reservoirs ${ }^{[7]}$. Less attention is paid to the ecological water supply potential of the upstream reservoir to BYD Lake. With the continuous improvement of the water supply and supporting works of the middle route of the South-to-North Water Transfer Project, as well as the implementation of water-saving measures, the water supply target and water supply volume of the upstream reservoir will undergo major chang-es. Only by clarifying the water replenishment potential of the upstream reservoirs to BYD Lake under different inflow frequencies can we coordinate and cooperate with the Yellow Water Diversion and the Middle Route Water of the South-to-North Water Diversion to better manage and utilize water resources. Based on the data collected from the WK, XDY, and AGZ in the Daqing River mountainous area from 2001 to 2018, the inflow and water supply conditions of the reservoir are analyzed. And the conditions of the reservoir under different incoming water conditions and continuous dry years are analyzed. The ecological replenishment potential of BYD Lake can provide a theoretical basis for the ecological replenishment scheduling of BYD Lake.

\section{The study area}

Daqing River is an important tributary in the middle of the Haihe River Basin. Its longitude is $113^{\circ} 39^{\prime}-116^{\circ} 10^{\prime}$ and latitude is $38^{\circ} 23^{\prime}-40^{\circ} 09^{\prime}$. It covers four provinces, Shanxi, Hebei, Beijing and Tianjin, with a basin area of $43000 \mathrm{~km}^{2}$.

\footnotetext{
*Corresponding author: daiyanyu_dyy@163.com
} 
The four seasons are clearly distinguished, with less precipitation and dry climate in spring, more rain and high temperature in summer, significant temperature difference between day and night in autumn, and cold and less snow in winter. The temperature distribution in the upper reaches of the basin gradually decreases from south to north and from low altitude to high altitude. Baiyangdian Lake is a natural lake in the middle of Daqing River Basin. It is $39.5 \mathrm{~km}$ long from east to west and $28.5 \mathrm{~km}$, wide from north to south, with a total area of $366 \mathrm{~km} 2$. AGZ, WK and XDY are the major reservoirs in the upper reaches of Daqing River that can supply ecological water to BYD Lake. As shown in Fig. 1, AGZ is a large reservoir in the upper reaches of Zhongyishui River, with a total storage capacity of 309 million cubic meters and a basin area of $476 \mathrm{~km}^{2}$. WK is a large reservoir on the Shahe River, the upper source of the Zhulong River, with a total storage capacity of 1.389 billion $\mathrm{m}^{3}$, a controlled basin area of $377 \mathrm{~km}^{2}$, and a normal water level of $200.4 \mathrm{~m}$, corresponding storage capacity of 699.7 million $\mathrm{m}^{3}$. XDY Reservoir is a large reservoir in the middle reaches of the Tanghe River, with a total storage capacity of 1.258 billion cubic meters, a controlled basin area of $4420 \mathrm{~km}^{2}$, and a normal water level of $140.5 \mathrm{~m}$, corresponding storage capacity of 594.7 million $\mathrm{m}^{3}$.

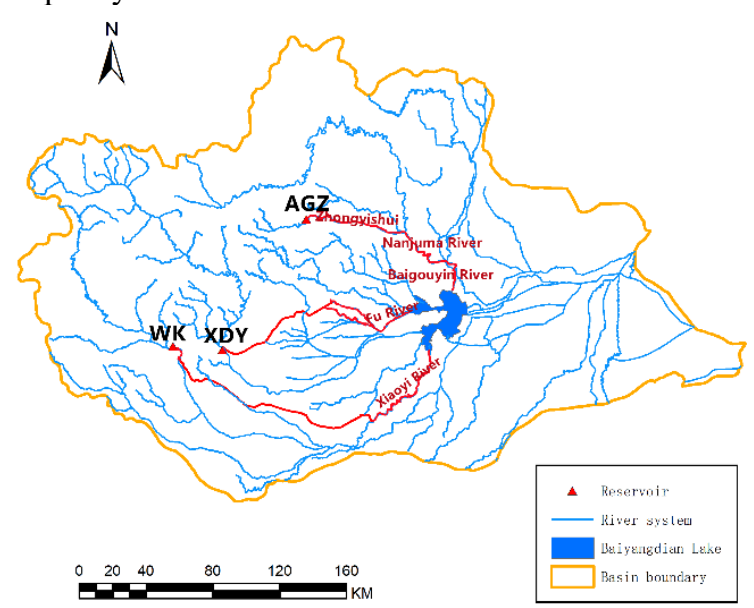

Fig. 1 Study area

\section{Current status of ecological water replenishment}

The amount of water entering Baiyangdian Lake mainly includes the amount of natural inflow, the amount of replenishing water from upstream reservoirs, and the amount of inflow of inter-basin water transfer. From 1981 to 2006, the ecological water replenishment of Baiyangdian Lake mainly came from the upstream reservoirs -WK, XDY, AGZ. During this period, the three reservoirs accumulated water replenishment 22 times, and the cumulative water replenishment reached 730 million $\mathrm{m} 3$. During the period, in the autumn of 2003, the water level of Baiyangdian Lake was too low again. Hebei Province transferred water from the Yuecheng Reservoir to replenish Baiyangdian Lake and supplied 160 million m3. From 2006 to 2011, the Yellow River water entered Baiyangdian Lake through the Weishan Yellow River
Diversion Project. During this period, the Yellow River was diverted five times to make up the lake, and the accumulated water supply amounted to 509 million $\mathrm{m}^{3}$.

The Middle Route of the South-to-North Water Diversion Project was opened in 2014. As of June 21, 2020, the first phase of the South-to-North Water Diversion Project has transferred a total of 30.6 billion $\mathrm{m} 3$ of water, of which 8 billion cubic meters have been supplied to Hebei Province. Since 2017, the mid-line trunk line project has used the surplus water during the flood season, and through optimized scheduling, the existing sluice gates and water outlets have been activated. It has passed 7 sluice gates/outlet gates (Shahebei, Tanghe, Puyang River, Zhengjiazuo, Baohe, Beiyishui, Beiju) implement ecological water replenishment to rivers and lakes and wetlands in the water receiving area. In the previous period from 2015 to 2018 , the ecological water replenishment of Baiyangdian Lake mainly came from WK and XDY, with a cumulative water replenishment of 159 million $\mathrm{m} 3$ from the two reservoirs. In 2017-2018, the middle route of the South-to-North Water Diversion Project provided 244 million m3 water to Baiyangdian Lake and its upstream rivers, 240 million $\mathrm{m} 3$ of water replenishment in 2018-2019, 800 million $\mathrm{m} 3$ of water replenishment in 2019-2020, and a total of 1.284 billion $\mathrm{m} 3$ of water replenishment. The "Water diversion project from the Yellow River to Hebei Province" started to supply water to the Baiyangdian Lake in 2018. From November 2018 to April 2019, it was the first time to divert the Yellow River into Hebei to make up 80 million m3 of water. After that, two water replenishments were carried out in August 2019 and August 2020, respectively. The water replenishment volume was 80 million $\mathrm{m} 3$ and $1.51 \mathrm{~m} 3$ respectively.

\section{Analysis of the potential of ecological water replenishment in the future}

\subsection{Analysis of water inflow from upstream of reservoir}

This paper analyzes the inflow volume and its linear trend of AGZ, WK and XDY from 2001 to 2018, as shown in the Fig. 2.

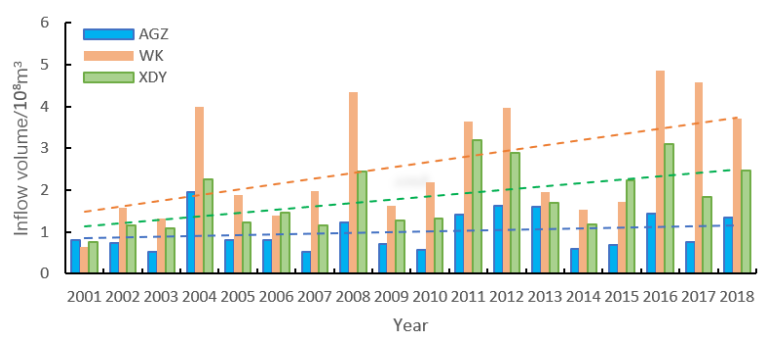

Fig. 2 Interannual variation of inflow volume According to the linear trend change, the inflow of the three reservoirs showed an increasing trend, among which WK was the most obvious, followed by XDY. The 
characteristic annual inflow value of the three reservoirs is inconsistent. According to the analysis of the inflow water data from 2001 to 2018 , the average annual inflow of AGZ is about 101 million $\mathrm{m}^{3}$. The annual average inflow from WK is about 260 million $\mathrm{m}^{3}$; The average inflow for many years is about 182 million $\mathrm{m}^{3}$. MannKendall trend test method is a non-parametric statistical test method recommended by the World Meteorological Organization and has been widely used. Its advantage is that it does not require samples to meet a certain distribution, nor is it interfered by a few outliers, and its calculation is relatively convenient ${ }^{[8]}$. Mann-Kendall trend test method and P-III frequency curve are used to analyze the inflow of reservoir water.

According to the calculation results, in terms of the trend of change, the upstream inflow from AGZ had no obvious trend of change, while the upstream inflow from WK and XDY showed a significant upward trend. The upward trend of the inflow of runoff from WK exceeded the significance level of 0.05 , while that of XDY exceeded the significance level of 0.01 . The increasing trend of the inflow runoff is the most obvious in XDY. At the same time, from the P-III frequency analysis, it can be concluded that the inflow of water in WK, XDY and AGZ is 420 million $\mathrm{m}^{3}, 280$ million $\mathrm{m}^{3}$ and 150 million $\mathrm{m}^{3}$ respectively in the wet year. The average year is 260 million $\mathrm{m}^{3}, 182$ million $\mathrm{m}^{3}$ and 101 million $\mathrm{m}^{3}$, respectively. Dry years are 120 million $\mathrm{m}^{3}, 100$ million $\mathrm{m}^{3}$ and 62 million $\mathrm{m}^{3}$ respectively.
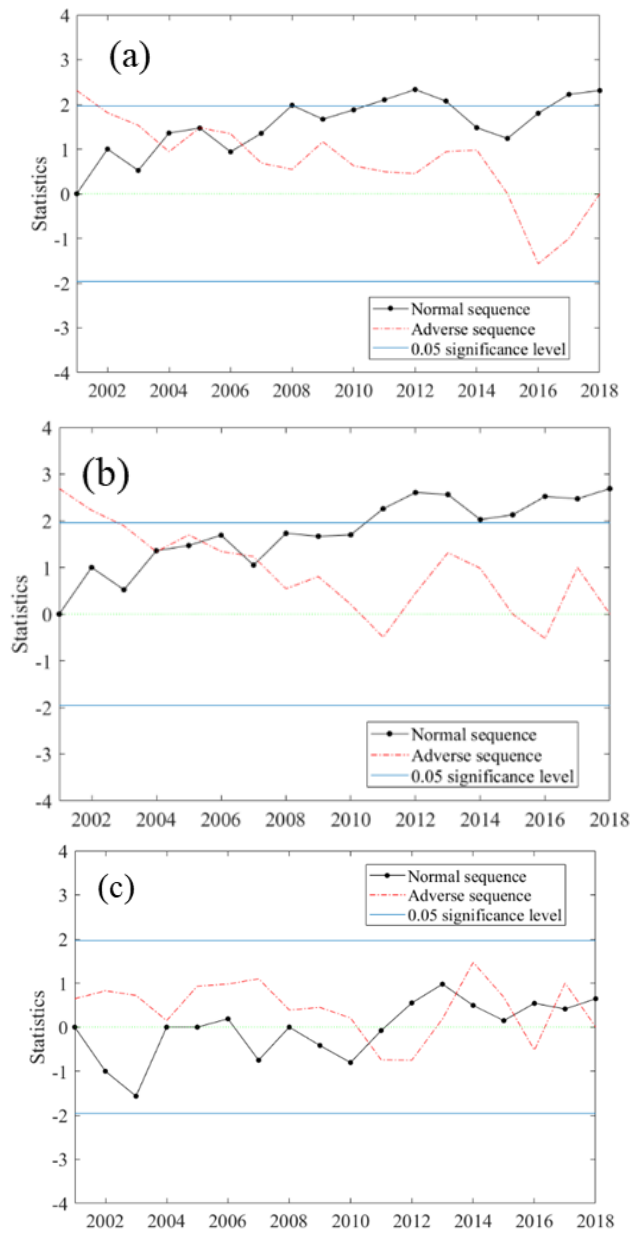

Fig 4. Inbound runoff M-K trend test results(a: WK; b: XDY; c: AGZ)
Table1 Inbound runoff in different years (million $\mathrm{m}^{3}$ )

\begin{tabular}{cccc}
\hline & Wet year & $\begin{array}{c}\text { Average } \\
\text { year }\end{array}$ & Dry year \\
\hline WK & 420 & 260 & 120 \\
XDY & 280 & 182 & 100 \\
AGZ & 150 & 101 & 62 \\
Total & 850 & 543 & 282 \\
\hline
\end{tabular}

\subsection{Ecological water replenishment potential}

The future ecological water replenishment potential of the WK, XDY, AGZ is mainly derived from the water supply originally provided for cities and industries after the supporting project of the middle route of the South-toNorth Water Transfer Project in Hebei Province is effective. Therefore, the maximum ecological water replenishment potential of the upstream reservoir to BYD Lake $=$ the original ecological water replenishment amount + the urban and industrial water consumption of the mid-line water replacement of the South-to-North Water Diversion Project. According to the analysis of the water supply situation of the upstream reservoirs in the past 20 years, the average maxi-mum ecological water replenishment of the three reservoirs is 279 million $\mathrm{m}^{3}$. Considering the changes in runoff into the reservoir under diff-erent incoming water conditions, the maxi-mum ecological water replenishment volume of up-stream reservoirs varies greatly, and the eco-logical water replenishment volume in wet years will increase significantly, with the maximum reaching 541 million $\mathrm{m}^{3}$ and the minimum being only 81 million $\mathrm{m}^{3}$.

According to the "Hebei Province Ground-water Overexploitation Comprehensive Treat-ment Plan", on the basis of the original plan, half of the water replenishment potential is adjusted to replace the groundwater overexploitation in the basin, and promote the gradual restoration of the groundwater level in the BYD Lake Basin. The amount of water used to maintain ecological water in the river and supplement BYD Lake water in the years of abundant, normal and dry water is ${ }^{3} 20$ million $\mathrm{m}^{3}$, 200 million $\mathrm{m}^{3}$, and 50 million $\mathrm{m}^{3}$, respectively.

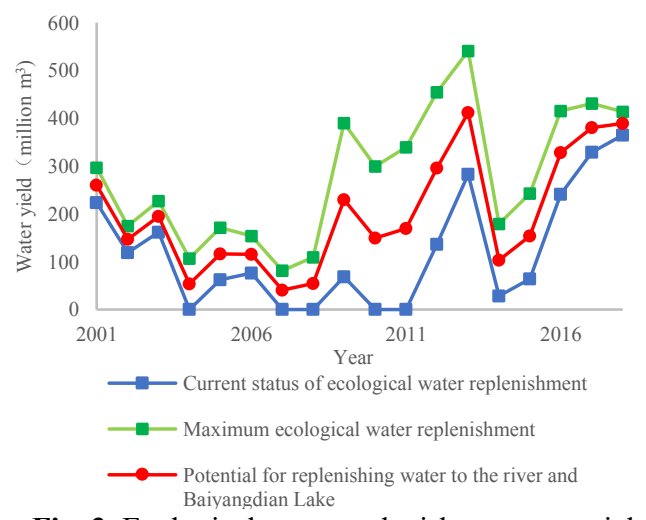

Fig. 3. Ecological water replenishment potential

\subsection{Ecological water replenishment potential in consecutive dry years}

From 2001 to 2018, through analysis of the inflow runoff 
of the three reservoirs, it was found that the years 2001 to 2003 and 2005 to 2007 were relatively dry years, and the average annual runoff into the reservoir was about 330 million $\mathrm{m}^{3}$, which was only $67 \%$ of annual average inflow runoff, with frequency between $75 \%$ and $95 \%$. At the same time, from December 2000 to February 2003, the water level in BYD Lake was too low. This situation reappeared in May 2003 and lasted until March 2004. From the results of ecological water replenishment in Figure 6, it can be seen that in the consecutive dry years from 2001 to 2003 and 2005 to 2007 , the average maximum ecological water replenishment for many years was about 184 million $\mathrm{m}^{3}$. Excluding the overex-ploitation used to replace groundwater, the average riverbed replenishment potential for many years is about 146 million $\mathrm{m}^{3}$.

\section{Conclusion}

The research on the ecological water supply potential of BYD Lake by reservoirs in Daqing River mountainous area provides a theoretical basis for the joint deployment of multiple water sources in the future. After replacing the original industrial and urban water use in the middle route of the South-to-North Water Transfer Project, the upstream reservoir will have a maximum water supply potential of 541 million $\mathrm{m}^{3}$ for the downstream river and BYD Lake, and the minimum is only 81 million $\mathrm{m}^{3}$. Considering that half of the water is reserved for groundwater replenishment and alleviating the problem of groundwater overexploitation, the water repleni-shment potential for maintaining ecological water in the river and supplementing the water volume of BYD Lake in the rich, normal and dry years are 320 million $\mathrm{m}^{3}$ and 200 million $\mathrm{m}^{3}, 50$ million $\mathrm{m}^{3}$ respectively. after deducting the losses along the way, the upstream reservoir cannot meet the ecological water demand of BYD Lake; under the conditions of continuous dry years, the multi-year average value of the river's water replenishment potential is about 146 million $\mathrm{m}^{3}$. The research results show that the ecological water replenishment potential of the upstream reservoir to BYD Lake varies greatly in different years. Therefore, the joint deployment of multiple water sources and their encounters with drought will be the focus of the next step.

\section{Acknowledgements}

This study was financially supported by the National Key Research and Development Plan of China (No. 2018YFC0406506).

\section{References}

1. W. Yang, Y. Zhao,Q. Liu, T. SUN, J. Lake Sci., 32(2) : 294-308(2020)

2. J. Yin, W. Cheng, L. Yan, X. Chen, Water Resources Protection, 25(1):52-58 (2009)

3. K. WANG, H. LI, A. WU, M. LI, Y. ZHOU, W. LI, Acta Geoscientica Sinica, 39(5): 549-558(2018)
4. L. LI, Journal of Agricultural Catastro-phology, 3(23) : 22-23(2013)

5. M. LIU, C. LU, C. MA, J. OU, Resources Science, 33(8): 1446-1453(2011)

6. J. ZHANG, X. ZHANG, H. XIAO, Water Resources and Hydropower Engineering, 50( 7) : 64-69(2019)

7. X. Li, University of Jinan(2020)

8. H.B Mann . Econometrica, 13(3):245-259(1945) 